\title{
Allogeneic Large Multivalent Immunogen Melanoma Vaccine LP2307
}

National Cancer Institute

\section{Source}

National Cancer Institute. Allogeneic Large Multivalent Immunogen Melanoma Vaccine

LP2307. NCI Thesaurus. Code C78862.

A cancer vaccine, containing human-specific large multivalent immunogen (LMI) isolated from plasma membrane fractions of the melanoma cell lines MSM-M1 and MSM-M2, with potential immunostimulating and antineoplastic activities. Upon administration, allogeneic large multivalent immunogen melanoma vaccine LP2307 may stimulate a CD8+ cytotoxic T lymphocyte (CTL) response against melanoma tumor cells that express melanoma-specific LMI. 